\title{
Características das populações em Terras Indígenas na região de influência da Usina Hidrelétrica de Belo Monte, estado do Pará. ${ }^{1}$
}

\author{
Ricardo de Sampaio Dagnino²
}

\section{Resumo}

Este trabalho pretende contribuir com a caracterização das populações residentes em Terras Indígenas localizadas na região de influência da Usina Hidrelétrica de Belo Monte, no estado do Pará. Trata-se da maior hidrelétrica do Brasil e os efeitos de sua construção tem sido objeto de diversos levantamentos que se debruçam sobre as alterações relativas aos ambientes naturais, mas também referentes aos efeitos sobre as populações. Nesse trabalho, fruto de uma pesquisa realizada por Dagnino; Estanislau (2015), foram analisadas 11 Terras Indígenas, que a partir do método de área mínima comparável foram agrupadas em oito unidades espaciais nas quais foram calculados 25 indicadores, baseados nos dados dos Censos de 2000 e 2010 e Contagem 2007, do Instituto Brasileiro de Geografia e Estatística (IBGE). Os resultados mostram que os indicadores seguem algumas tendências verificadas no Brasil como um todo entre 2000 e 2010, tal como: envelhecimento da estrutura etária, aumento da renda aliado à redução do analfabetismo, diminuição da razão de sexo e forte presença de imigrantes de curta distância.

Palavras-chave: Indicadores demográficos, Indicadores socioeconômicos, Censos demográficos, Distribuição espacial.

\section{Introdução}

A Usina Hidrelétrica de Belo Monte (UHEBM), no estado do Pará, é a maior Usina Hidrelétrica do Brasil e uma das maiores do mundo. Os efeitos da construção e da entrada em operação desse empreendimento têm sido objeto de diversos levantamentos, que se debruçam sobre as alterações relativas aos ambientes naturais (SEVÁ FILHO, 2005), mas também referentes aos efeitos sobre as populações de modo geral (MAGALHÃES; MORAL HERNÁNDEZ, 2009), a saúde (GRISOTTI, 2016), os conflitos sociais (HERRERA; MOREIRA, 2013) e até os efeitos sobre a deslegitimação do discurso de grupos sociais que se opõem às políticas oficiais de desenvolvimento (MORAL HERNÁNDEZ; MAGALHÃES, 2011).

Este trabalho está incluído na proposta de uma caracterização da população residente nas 11 Terras Indígenas (TI) localizadas na região de influência da Usina Hidrelétrica de Belo Monte (UHEBM) e de elaboração de uma projeção demográfica, que resultou em um relatório que detalha os procedimentos envolvidos (DAGNINO; ESTANISLAU, 2015).

A região abrange 12 municípios no estado do Pará: Altamira, Anapu, Brasil Novo, Medicilândia, Novo Repartimento, Pacajá, Placas, Rurópolis, São Félix do Xingu,

\footnotetext{
1 Trabalho submetido para apresentação no IV Seminário População, Espaço e Ambiente - 2017, Limeira, São Paulo, organizado pelo Grupo de Trabalho População, Espaço e Ambiente (GT PopEA) da Associação Brasileira de Estudos Populacionais (ABEP). Mais informações sobre o evento: https://ivseminariopopea.wordpress.com/.

${ }^{2}$ Geógrafo e Demógrafo, Pesquisador de Pós-Doutorado na Universidade Estadual de Campinas.
} 
Senador José Porfírio, Uruará, Vitória do Xingu. As TI estudadas são: Apyterewa, Araweté, Koatinemo, Trincheira Bacajá, Kararaô, Arara, Cachoeira Seca, Xipaya, Kuruaya, Paquiçamba e Arara da Volta Grande do Xingu (Figura 1).

\section{Terras Indigenas e Municípios da Região da Usina de Belo Monte - Pará - Brasil}
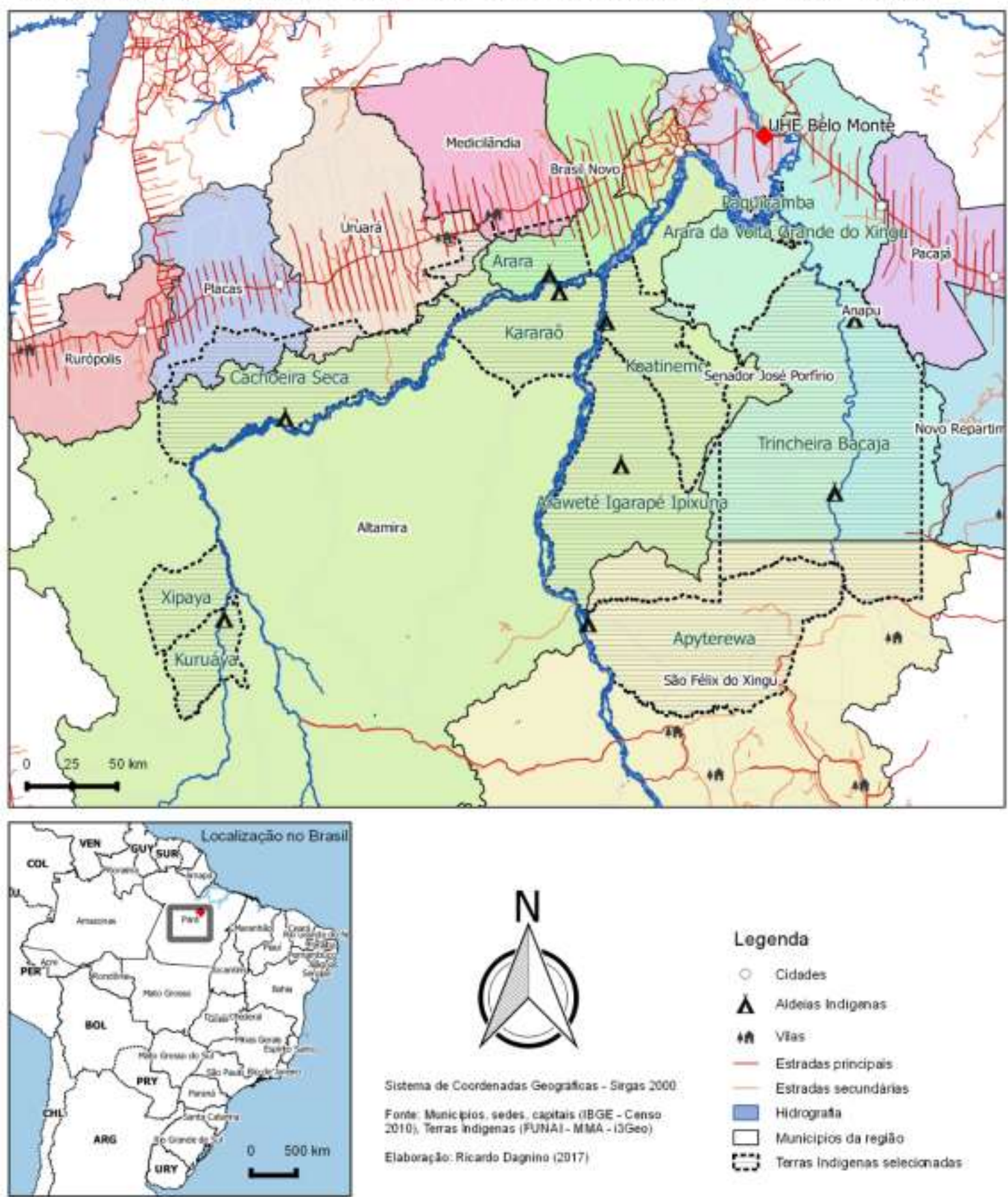

Figura 1 - Terras Indígenas e municípios na região de influência da Usina Hidrelétrica de Belo Monte, Pará, Brasil.

As características populacionais foram analisadas a partir de indicadores (detalhados no item Materiais e Métodos) criados com base nos dados levantados nos Censos de 2000 e 2010 e Contagem 2007, realizados pelo Instituto Brasileiro de Geografia e Estatística (IBGE). As análises foram feitas com base nos dados agregados por setor 
censitário, que é a menor unidade de representação dos dados coletados nesses levantamentos.

A partir do Censo 2000, o IBGE disponibilizou as malhas dos setores censitários, que é a menor área de disseminação dos dados censitários e é delimitada com base em critérios operacionais (uma área com aproximadamente 300 domicílios nas zonas urbanas ou que seja viável de ser percorrida por um agente censitário na zona rural) e, também, geográficos de maneira que seus limites levam em consideração os limites de bairros, parques e, sobretudo a partir do Censo 2007, as Terras Indígenas e Unidades de Conservação. Entretanto, como há alteração nos limites dos setores censitários ao longo do tempo foi necessário adotar uma metodologia de compatibilização das malhas, criando-se uma unidade espacial comparável no tempo.

Assim, o objetivo principal desse trabalho é caracterizar a população das $\mathrm{Tl}$ da região da UHEBM com base em indicadores socioeconômicos e demográficos e analisar a evolução desses indicadores entre 2000 e 2010.

\section{Materiais e Métodos}

\section{Compatibilização de malhas}

Em um ambiente de Sistema de Informação Geográfica (SIG) foram associados os dados estatísticos aos planos de informação com dados geoespaciais em forma de polígono referentes aos setores censitários dos últimos censos e contagem (IBGE, 2003b, 2008, 2011b) e Terras Indígenas (FUNAI, 2014). Do total de setores dos municípios, foram selecionados aqueles que, em cada ano, situavam-se dentro das $\mathrm{TI}$, em seguida, foram incluídos os respectivos dados estatísticos agregados por setores.

O processo de criação de uma única malha adaptada dos setores dos 12 municípios foi realizado a partir da malha digital do Censo 2010 por ser a malha que, comparada com as dos levantamentos anteriores, possui a melhor qualidade/acurácia, em relação à compatibilidade entre os limites dos setores (geometrias) e os objetos no solo (geografia) por ter sido elaborada a partir de imagens de satélite em escala de maior detalhe e trabalhos de campo por parte do IBGE. Ao final têm-se um plano de informação que permite comparações no tempo onde cada uma das áreas foi classificada como uma Unidade espacial comparável no tempo (Figura 2).

A metodologia utilizada assemelha-se à de Áreas Mínimas Comparáveis (AMC), empregada pelo Instituto de Pesquisa Econômica Aplicada (IPEA), detalhada em Reis et al. $(2007,2011)$, que resulta em agregação de áreas do menor número para que as comparações intertemporais sejam geograficamente consistentes.

Por conta desse procedimento, visando garantir a comparação dos indicadores no tempo, reduziu-se as $11 \mathrm{TI}$ para oito unidades espaciais comparáveis (Figura 3): "Apyterewa + Trincheira Bacaja (porção sul)", "Arara (exceto porção sudoeste)", "Arawete Igarape Ipixuna", "Cachoeira Seca + Arara (porção sudoeste)", "Kararaô", "Koatinemo", "Trincheira Bacaja (porção norte) + Arara VGX + Paquiçamba", "Xipaya + Kuruaya".

Em decorrência da metodologia adotada, que privilegia a análise diacrônica (ao longo do tempo) e em função das diferentes formas de desenhar os setores censitários (que em 2010 levavam em conta os limites das TI), percebe-se que os agrupamentos 
comparáveis abarcam setores censitários que ficam fora das Terras Indígenas. Como resultado disso, acaba-se incluindo nas TI populações que nunca estiveram dentro delas (isso é mais verdadeiro para os domicílios localizados nas bordas mais externas dos setores e mais distantes das TI). Isso pode ajudar a entender porque na maior parte das unidades espaciais a população indígena não é predominante, embora em duas delas $100 \%$ da população seja autodeclarada indígena; e em grande parte delas exista elevado percentual de população parda.

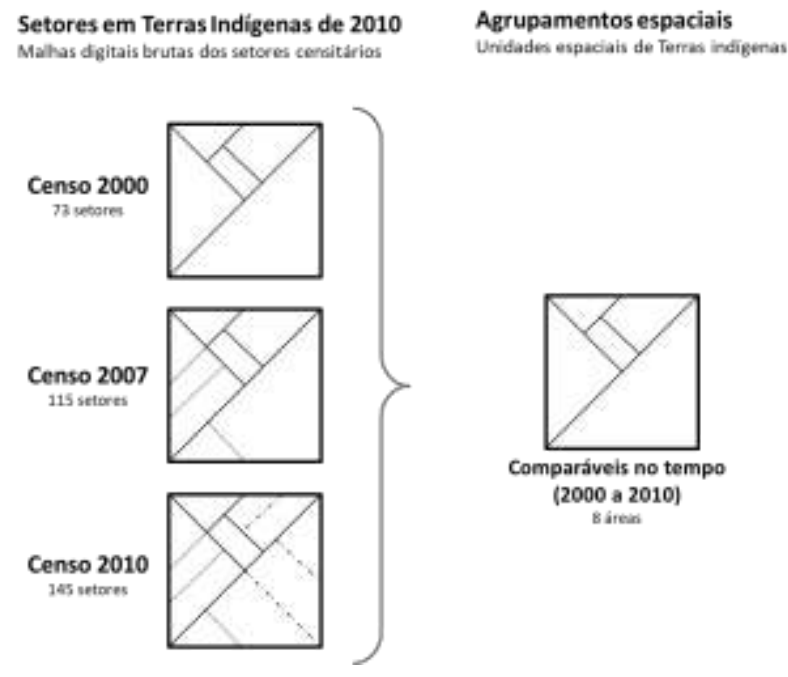

Figura 2 - Diagrama esquemático com a metodologia de áreas mínimas comparáveis de Terras Indígenas, com a quantidade de setores em cada censo. 

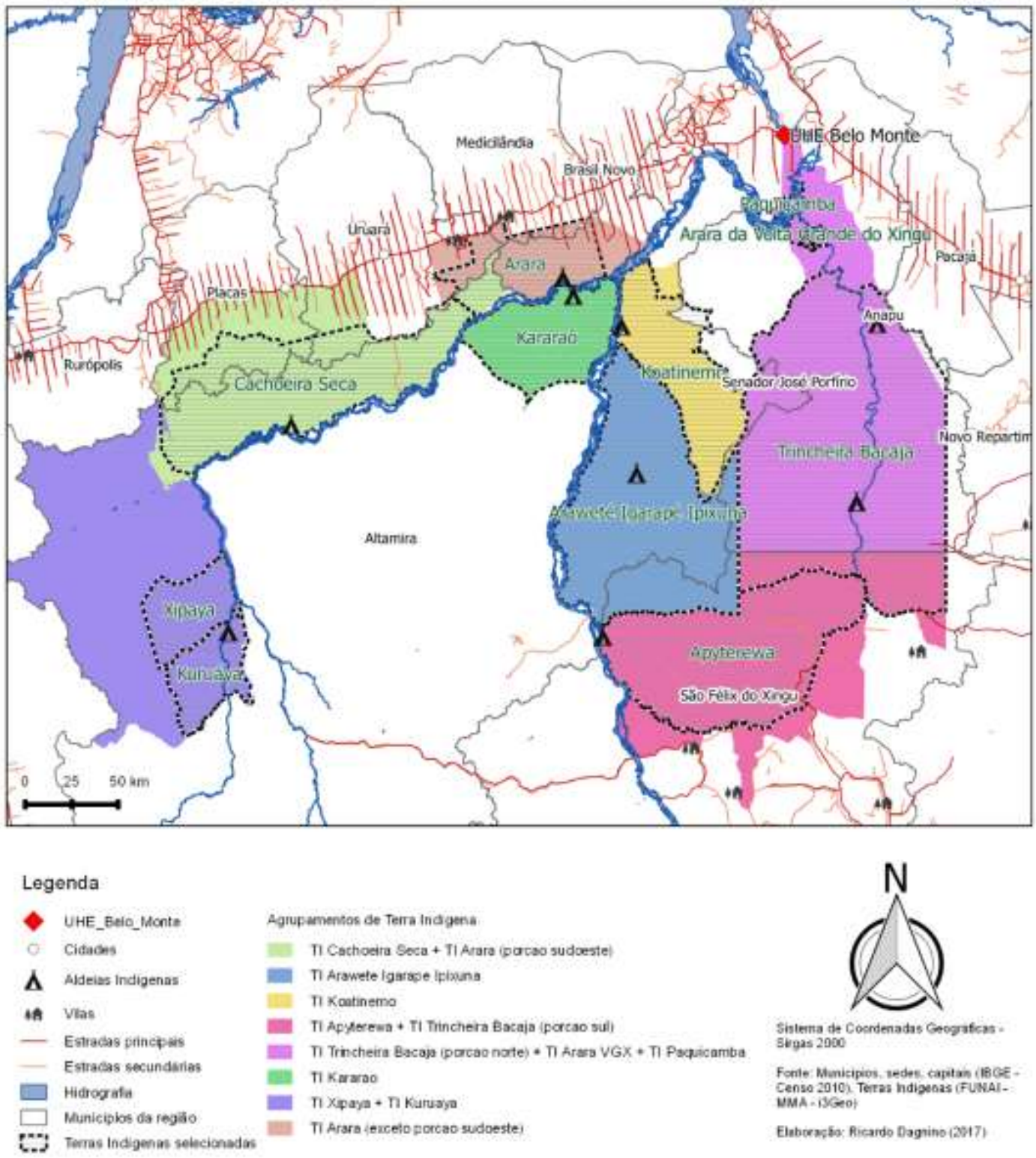

Figura 3 - Mapa com a localização e os limites dos oito agrupamentos de Terras Indígenas comparáveis entre 2000 e 2010, na região da Usina Hidrelétrica de Belo Monte, Pará, Brasil.

\section{Indicadores}

Os indicadores foram calculados segundo as indicações da RIPSA (2008) o que permite fácil comparação com outros levantamentos e também acompanhar as alterações das características dessas populações ao longo do tempo (JANNUZZI, 2001). Foram utilizadas as informações disponíveis nos dados agregados por setor censitário que derivam das respostas para as questões aplicadas ao universo da população (IBGE, 2003b, 2008, 2011b).

Os levantamentos do IBGE possuem diferenças entre si, em relação às questões aplicadas. Existem questões que estão presentes em todos os levantamentos como número de residentes, sexo e idade. Entretanto, existem diferenças em relação a Censo ou Contagem, como por exemplo as questões sobre migração, que só existem 
na Contagem, e a informação sobre renda, que está disponível somente nos Censos. Também, existem alterações que ocorrem ao longo do tempo: questões sobre raça e cor, que estão presentes no Censo 2010, não existiam anteriormente para o universo.

A seguir, veremos os principais indicadores para a caracterização dessas populações, segundo os limites desse trabalho:

\section{Razão de Sexos}

A Razão de Sexos (RS) representa o número de homens para cada 100 mulheres em um determinado espaço e permite verificar mais facilmente a relação quantitativa entre os sexos: se a razão for igual a 100, significa que o número de homens e de mulheres se equivale; acima de 100, o número de homens é maior; se for menor que 100, predominam as mulheres (RIPSA, 2008, p. 60).

As diferenças entre número de homens e mulheres são influenciadas por taxas de migração e efeitos de seletividade nos processos migratórios, e por causa das taxas de mortalidade diferenciadas por sexo e idade. Segundo RIPSA (2008, p. 61): "A maioria da população brasileira é composta de pessoas do sexo feminino, reflexo da sobremortalidade masculina, sobretudo nas faixas etárias jovens e adultas, decorrentes da alta incidência de óbitos por causas violentas. Apenas na região Norte e na região Centro-Oeste (esta em 1991 e 1996), o percentual de homens supera a de mulheres, por razões socioeconômicas que condicionam o emprego majoritário de mão-de-obra masculina".

Assim, esse indicador auxilia na compreensão de fenômenos sociais que podem estar influenciando a diferença quantitativa entre os sexos (como, por exemplo, migrações, mercado de trabalho, organização familiar, morbi-mortalidade) e também identificar áreas prioritárias para estudos de gênero a respeito dos fatores condicionantes das variações encontradas (RIPSA, 2008, p. 60).

\section{Indicadores de estrutura etária}

A estrutura etária é resultante da composição da população segundo os grupos etários e sua análise ao longo do tempo permite analisar processos conhecidos como transição demográfica (CARVALHO; WONG, 2008; BRITO, 2008) e envelhecimento populacional (WONG; CARVALHO, 2006).

Indicadores desse tipo são relevantes para o estudo de pequenas áreas, pois fornecem informações sobre a renovação da população (quando existe grande percentual de crianças) ou seu envelhecimento.

A seguir, são apresentados os indicadores de estrutura etária utilizados, lembrando que nos cálculos considera-se somente a população residente com idade conhecida, ou seja, excluída a população de idade ignorada (RIPSA, 2008):

+ Percentual de jovens: é o percentual de pessoas menores de 15 anos (0 a 14 anos) em relação à população total com idade conhecida. A população nesse grupo etário, equivale a uma população considerada como economicamente dependente (RIPSA, 2008).

+ Percentual de adultos: equivale ao percentual de pessoas entre 15 e 59 anos em relação à população total com idade conhecida. E considerada como população economicamente potencialmente produtiva (RIPSA, 2008). 
+ Percentual de idosos: Percentual de idosos - que equivale às pessoas com $60 \mathrm{e}$ mais anos de idade na legislação brasileira (BRASIL, 2003) - em relação ao total de pessoas com idade conhecida. No tempo, o aumento dos idosos representa 0 envelhecimento da estrutura etária, estando associado à redução das taxas de fecundidade e de natalidade e ao aumento da esperança de vida (RIPSA, 2008, p. $68)$.

\section{Indicador de Renda}

A informação de renda é proveniente do rendimento nominal mensal da pessoa de 10 anos ou mais de idade, responsável pelo domicílio particular permanente (IBGE, 2003a, p. 15-17), ou seja, sem contar os demais domicílios (como os coletivos, por exemplo).

O rendimento nominal mensal inclui rendimento de trabalho e também o de outras fontes como rendimentos provenientes de aluguéis, aposentadoria, pensão, programas de auxílio e transferência de renda (como renda mínima e bolsa-escola). O rendimento do trabalho inclui o valor, real ou estimado, dos produtos ou mercadorias recebidas pelas pessoas com atividade na agricultura, silvicultura, pecuária, extração vegetal ou mineral, pesca e piscicultura. Entretanto, cabe notar que esta variável não inclui as trocas de produtos (escambo), prática muito comum na Amazônia, devido ao fato que estas trocas não envolvem valores monetários.

Para fins de comparação entre os rendimentos nos Censos 2000 e 2010 são necessários procedimentos descritos em Dagnino (2014, p. 74-75) tais como aplicar um deflator na renda para poder comparar dois momentos (BIAGIONI, 2013), levar em conta a alteração no salário mínimo no tempo e escolher adequadamente a variável a ser utilizada, pois há variação entre os levantamentos.

\section{Taxa de analfabetismo}

Este indicador apresenta o percentual de analfabetos ou, mais corretamente, o quociente entre a população analfabeta dentro de um grupo etário e a população total do mesmo grupo etário. Assim, apesar do nome consagrado na literatura, trata-se de um percentual e não uma taxa.

Foram utilizadas algumas convenções e pressupostos: (1) será utilizado o termo taxa de analfabetismo devido à sua consagração e ao amplo uso em estatísticas nacionais de diversos países; (2) para o cálculo, será utilizado o grupo etário de 10 anos ou mais como referência, no nominador e no denominador, devido a sua aderência à realidade amazônica; (3) quanto à definição de analfabeto, ele é categorizado pelo Censo como aquele que não sabe ler e escrever pelo menos um bilhete simples, no idioma que conhece; (4) níveis de analfabetismo acima de 5\% são considerados inaceitáveis, como reconhece a UNESCO (1993) apud RIPSA (2008, p. 92).

Além das implicações óbvias na caracterização dos aspectos educacionais, a taxa de analfabetismo possui um papel relevante na caracterização das condições de vida e de saúde da população ao ser utilizado como aproximação da sua condição socioeconômica (RIPSA, 2008, p. 92): "A situação de saúde das crianças é influenciada positivamente pela alfabetização da população adulta, sobretudo das mães". Em termos de políticas públicas esse indicador é muito importante, pois pessoas não alfabetizadas necessitam formas especiais de abordagem. 


\section{Indicadores de população migrante}

Os indicadores de população migrante neste trabalho são dois: (1) o percentual de imigrantes na população total residente, e (2) o percentual de população imigrante de cada região de origem, em relação ao total de população migrante.

Indicadores desse tipo são relevantes para os estudos de população em escala intramunicipal, pois fornecem informações quantitativas, sobre o volume de pessoas que chegam, e qualitativas, a respeito do local de origem dos imigrantes. Além disso, é possível pensar a contribuição das redes sociais formadas no local de origem como um impulsionador para a população se manter no local de destino (CUNHA et al., 2013).

Os deslocamentos de população no espaço são especialmente importantes em demografia e distinguem-se dos demais componentes de sua dinâmica (fecundidade e mortalidade) pelo menos sob dois aspectos, ressaltados por Renner e Patarra (1991, p.236): de um lado, a migração não apresenta uma dimensão biológica, diferente dos outros componentes; de outro, a redistribuição espacial da população influencia os efeitos decorrentes dos outros componentes.

No nível dos setores censitários, o migrante só pode ser encontrado nos dados da Contagem e, com relação à mais recente, conceitua-se como a pessoa que, sete anos antes da contagem, residia fora do município no qual residia em 2007.

Diante do exposto, foram calculados os percentuais de migrantes em relação à população total e os percentuais de migrantes segundo a origem, em relação ao total de migrantes. As origens do migrante podem variar entre outro país, municípios de outras UFs e as suas respectivas regiões (Norte, Nordeste, Sul, Sudeste, CentroOeste) ou outro município da mesma UF.

\section{Indicadores de cor ou raça}

Este indicador é formado pelos percentuais de residentes segundo cinco categorias autodeclaradas de cor ou raça: branca, preta, parda, amarela ou indígena. Esse indicador fornece uma caracterização da população no sentido cultural (em função do pertencimento a uma determinada cor/raça) e étnico (principalmente quando se trata de indígenas).

O IBGE, desde os seus primeiros Censos Demográficos, mantém três categorias básicas de cor ou raça (Branca, Preta, Parda) no questionário da amostra. No Censo Demográfico 1940 a categoria de cor/raça amarela foi incluída para dar conta da imigração japonesa ocorrida desde 1908 (LOMBARDI et al., 2013). Em 1991 a cor/raça indígena passou a ser incorporada no questionário da amostra (IBGE, 2011a, p. 15). Essas inclusões de categorias fizeram com que houvesse alteração no quesito, que passou de "cor", entre 1940 e 1991, para "raça ou cor", em 1991, e "cor ou raça" desde então (IBGE, 2011a, p. 15). Com o Censo 2010, a questão sobre cor ou raça passa a ser realizada também no questionário básico ou do universo.

Cabe lembrar que para o IBGE (2011c, p. 26), a categoria de cor/raça amarela é utilizada para aquela pessoa que se declarou de cor amarela, ou seja, de origem oriental: japonesa, chinesa, coreana, entre outras. Entretanto, sabe-se que muitas pessoas, que provavelmente não são instruídas corretamente pelos recenseadores, 
declaram-se como amarela, pois pensam que essa cor se refere à cor da pele e não à população de origem oriental.

Por um lado, existe um movimento que luta e defende a importância do uso das categorias preta e indígena por parte de descendentes de quilombolas e de povos indígenas, por outro, populações consideradas como tradicionais (ribeirinhas, seringueiras) e mesmo indígenas e descendentes de quilombolas que se situam ideologicamente afastados dos movimentos de reafirmação étnica assinalados acima, parecem optar pela cor/raça parda no momento da autodeclaração no Censo Demográfico (LOMBARDI et al., 2012, p. 104). Para estas populações que optam por se declararem pardos, Lombardi et al. (2012, p. 104) propõe estudos específicos aos quais acrescentaríamos a necessidade de se identificar quem são os autodeclarados amarelos, sobretudo em localidades sem imigrantes orientais.

\section{Resultados e Discussão}

Os indicadores foram calculados para todos os 8 agrupamentos espaciais de Terras Indígenas comparáveis no tempo, entre 2000 e 2010, e no Apêndice são apresentadas as tabelas com os dados processados para construção dos indicadores.

A Tabela 1 apresenta a quantidade de população nos agrupamentos em 2000, 2007 e 2010, e a taxa de crescimento demográfico entre 2000/2007, 2007/2010 e $2000 / 2010$. Percebe-se que a quantidade de residentes varia bastante, tanto entre as unidades, quanto ao longo do tempo. O agrupamento "TI Cachoeira Seca + TI Arara (porção sudoeste)" é que possui maior quantidade de população residente (9446 pessoas) e a TI Kararaô a que possui menor população (25 pessoas) - nessa $\mathrm{TI}$ a informação sobre a idade foi omitida por questões de sigilo estatístico pelo IBGE.

Tabela 1 - População residente em 2000, 2007 e 2010 e taxa de crescimento geométrico anual da população em cada período, segundo o agrupamento espacial ou localidade.

\begin{tabular}{l|rrr|rrr}
\hline Agrupamento espacial / localidade & \multicolumn{3}{|c|}{ População residente } & \multicolumn{3}{|c}{$\begin{array}{c}\text { Taxa de crescimento } \\
\text { geométrico anual }\end{array}$} \\
\hline Nome & 2000 & 2007 & 2010 & $\begin{array}{r}2000 / \\
2007 /\end{array}$ & $2000 /$ \\
2010 & 2010 \\
\hline TI Cachoeira Seca + TI Arara (porção sudoeste) & 9446 & 10269 & 11933 & 1,20 & 5,13 & 2,36 \\
TI Arawete Igarape Ipixuna & 378 & 483 & 393 & 3,56 & $-6,64$ & 0,39 \\
TI Koatinemo & 215 & 112 & 237 & $-8,90$ & 28,38 & 0,98 \\
TI Apyterewa + TI Trincheira Bacaja (porção sul) & 3052 & 8582 & 12673 & 15,92 & 13,88 & 15,30 \\
TI Trincheira Bacaja (porção norte) + TI Arara VGX + TI & 1548 & 3376 & 4251 & 11,78 & 7,98 & 10,63 \\
Paquiçamba & 297 & 525 & 669 & 8,48 & 8,41 & 8,46 \\
TI Xipaya + TI Kuruaya & 2872 & 1985 & 2486 & $-5,14$ & 7,79 & $-1,43$ \\
TI Arara (exceto porção sudoeste) & 25 & 342 & 59 & 45,31 & $-44,33$ & 8,97 \\
TI Kararaô & 17833 & 25674 & 32701 & 5,34 & 8,40 & 6,25 \\
\hline Agrupamentos espaciais (soma) & 340862 & 410432 & 491291 & 2,69 & 6,18 & 3,72 \\
\hline Municípios da região de Belo Monte & & & & & &
\end{tabular}

Na Figura 4 percebe-se uma diminuição do peso da população jovem (0 a 14 anos) e um aumento da população adulta (15 a 59 anos) em todos os agrupamentos, exceto na TI Koatinemo, onde ocorreu o contrário. No caso dos idosos (60 anos ou mais) 
houve aumento na maior parte dos casos, e apenas houve diminuição do peso nos grupos TI Arawete Igarape Ipixuna e nas TI Xipaya e Ti Kuruaya.

Em termos de razão de sexo, em 2000, a que possui maior é "TI Xipaya + TI Kuruaya" ( $R S=137,60)$, o que significa que há mais homens que mulheres $(137,6$ homens para cada 100 mulheres); em contrapartida, "TI Arawete Igarape Ipixuna" é o agrupamento com menor razão de sexo: a cada 100 mulheres há 96,88 homens (Ver tabelas no Apêndice). Em 2010, a maior RS continua sendo no agrupamento "TI Xipaya + TI Kuruaya", entretanto a TI Kararaô passa a ser o agrupamento com menor RS.

A Figura 5 apresenta a variação percentual de renda e da taxa de analfabetismo, dados disponíveis para os anos de 2000 e 2010. Percebe-se uma variação de renda positiva, ou seja, um aumento na renda da população nas Tls Apyterewa + TI Trincheira Bacaja (porção sul), TI Xipaya + TI Kuruaya (ambas com mais de 65\% de acréscimo na renda da população) e TI Trincheira Bacaja (porção norte) + TI Arara VGX + TI Paquiçamba. Nas demais Tls selecionadas houve um decréscimo da renda, sendo maior entre a população da TI Koatinemo (-44,35\%) e menor na TI Arara (exceto porção sudoeste).

A taxa de analfabetismo aumentou apenas na TI Arawete Igarape Ipixuna (6,56\%). Nas demais houve uma redução de $-11,64 \%$ na TI Arara (exceto porção sudoeste) a $-51,65 \%$ na TI Xipaya + TI Kuruaya. Um fato interessante que o gráfico permite visualizar é que a queda na taxa de analfabetismo foi mais intensa justamente onde houve aumento na renda. 


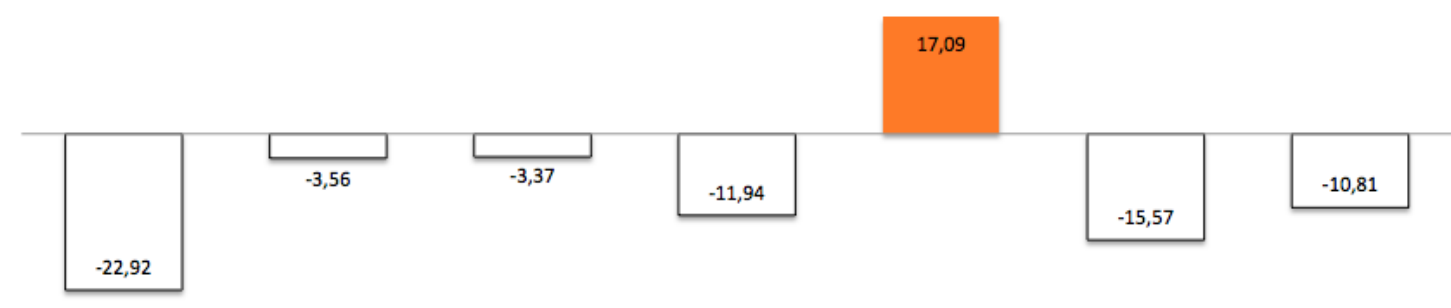

Adultos (15 a 59 anos)

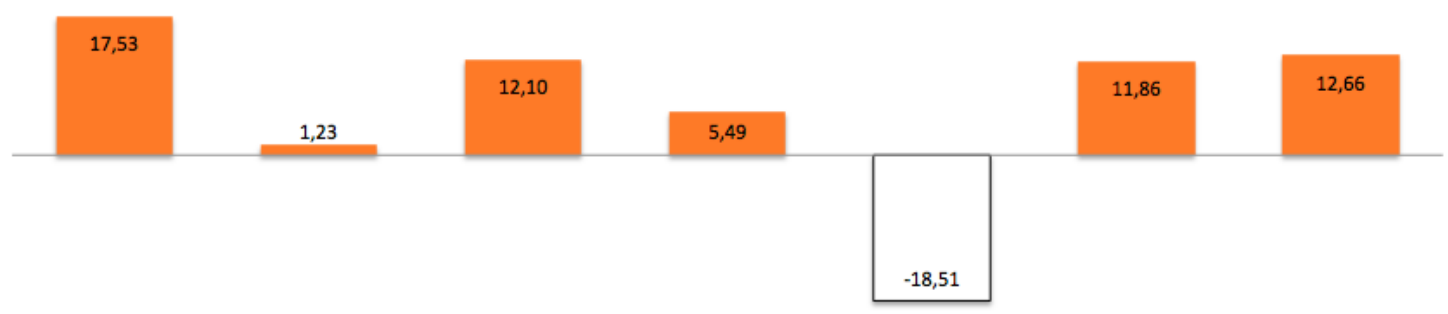

Idosos (60 anos ou mais)

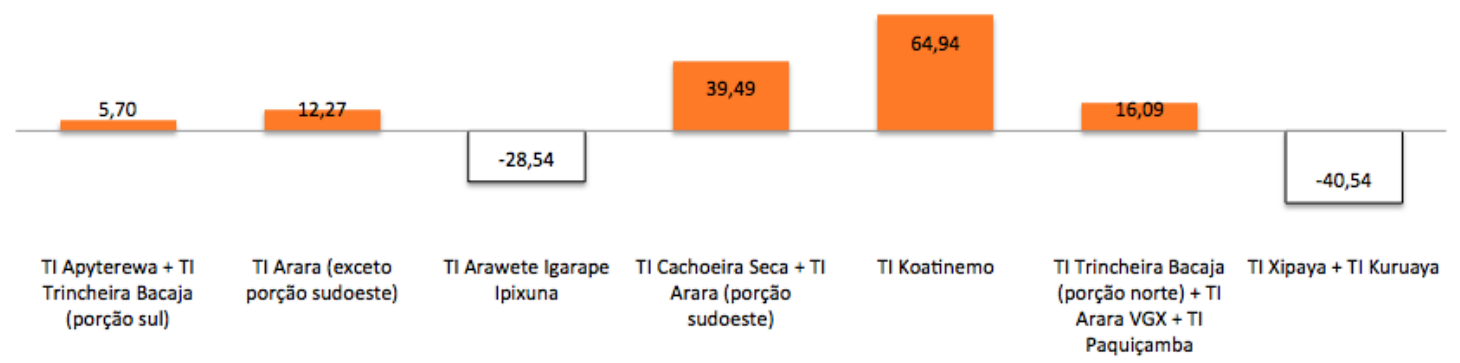

Figura 4 - Variação percentual da população entre 2000 e 2010, segundo o grupo etário, nos agrupamentos de Tls.

Em relação à queda no analfabetismo, chama a atenção a correlação negativa entre Renda e Taxa de analfabetismo, que é mais forte nos agrupamentos, como demonstram os gráficos abaixo (Figura 6), onde o $\mathrm{R}^{2}$ é maior em 2000 do que em 2010: no primeiro, $68 \%$ do aumento na renda era explicado pela diminuição na taxa de analfabetismo, ao passo que em 2010 , com $\mathrm{R}^{2}$ menor, ele ajuda a explicar $59 \%$ da correlação negativa entre taxa de analfabetismo e renda. 

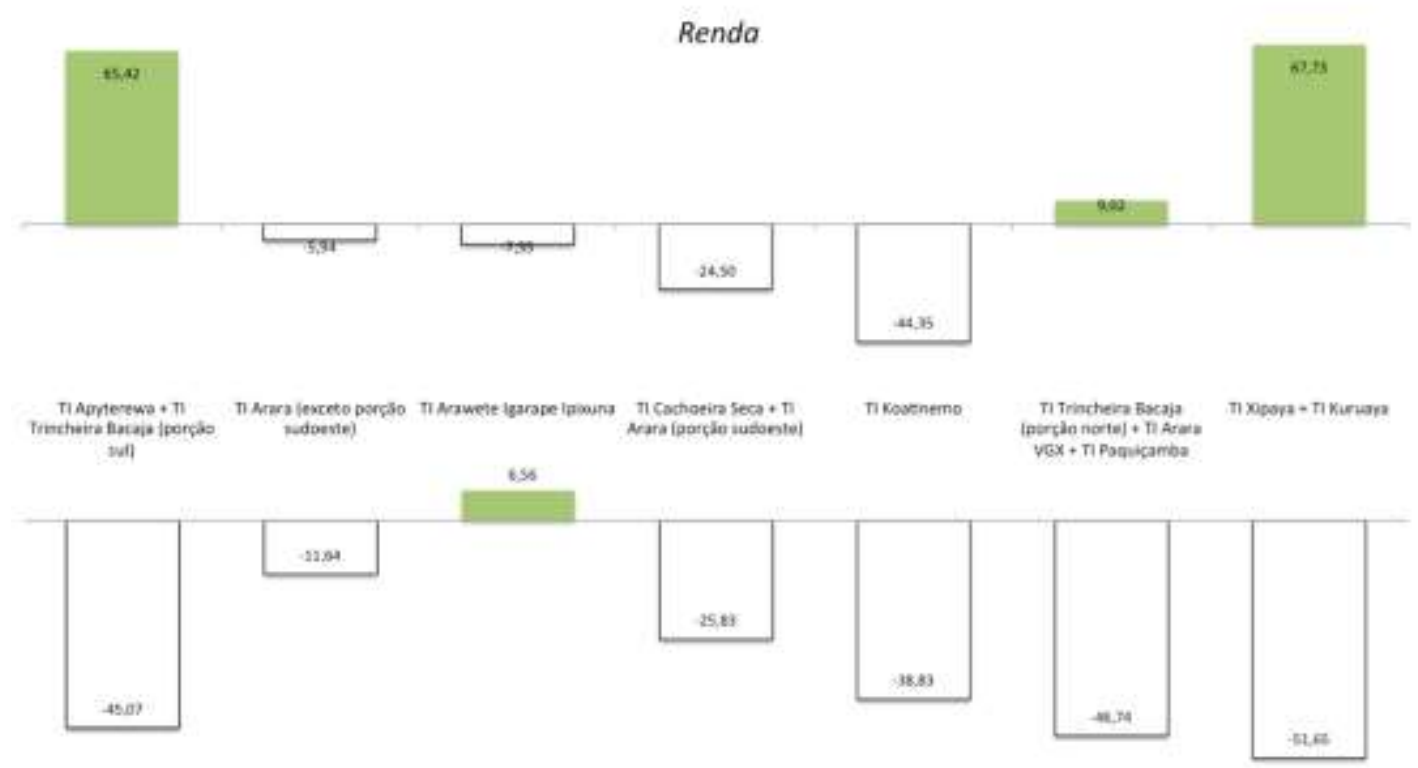

Taxa de analfabetismo

Figura 5 - Variação percentual da renda e da taxa de analfabetismo entre 2000 e 2010, segundo o agrupamento.
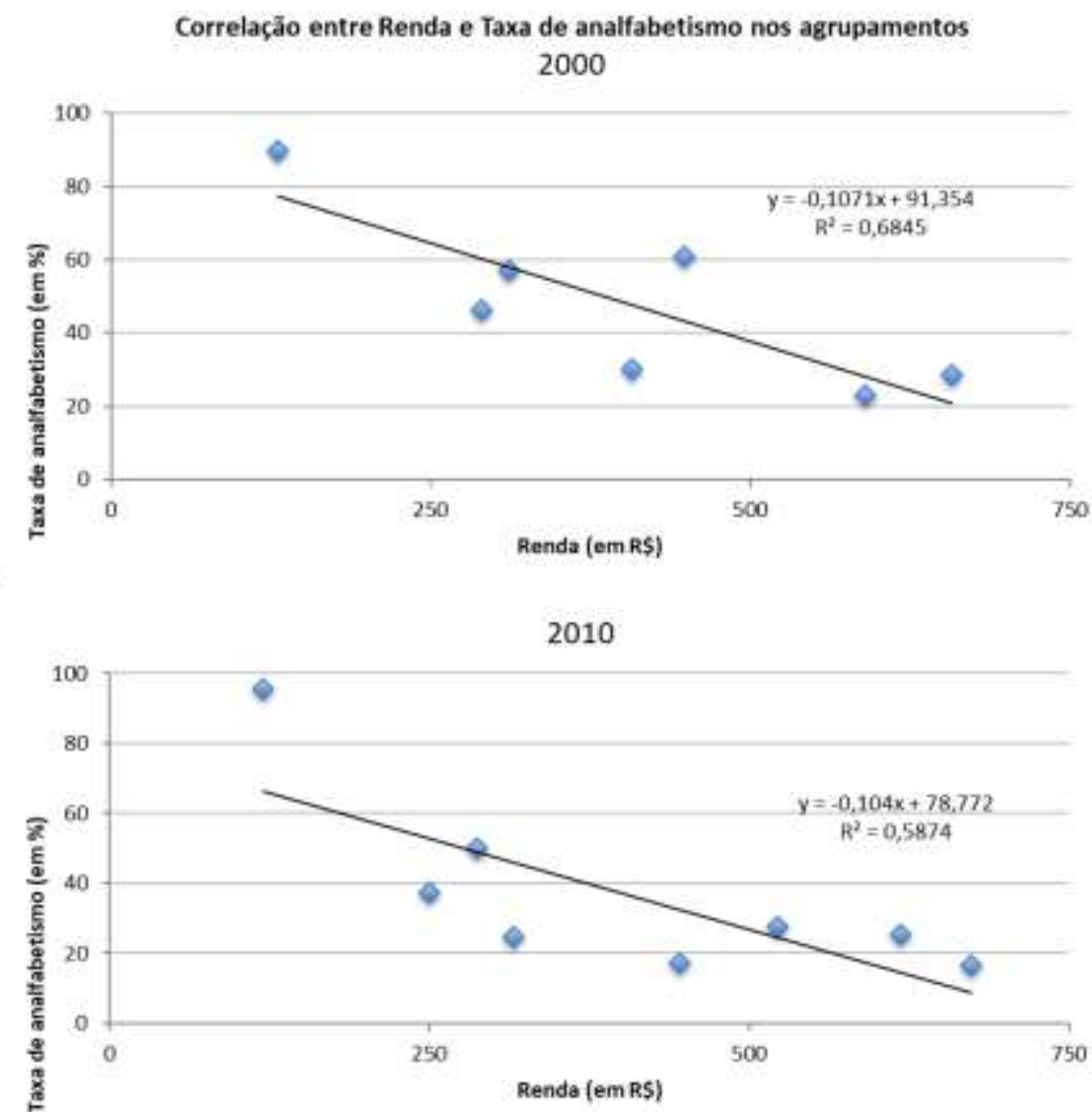

Figura 6 - Correlação entre taxa de analfabetismo e renda nos agrupamentos, em 2000 e 2010. 
A Figura 7 apresenta a distribuição percentual da população por cor ou raça. Nas TIs Arawete Igarape Ipixuna e TI Kararaô há apenas população indígena, enquanto na TI Cachoeira Seca + TI Arara (porção sudoeste), na TI Apyterewa + TI Trincheira Bacaja e na TI Arara (exceto porção sudoeste) há uma predominância de população autodeclarada como parda. É preciso ressaltar que isso não significa que a população nessas TIs com maioria parda não seja composta por indígenas, pois pode haver, na verdade, um entendimento diferenciado do conceito de cor ou raça entre os indígenas, com consequências diretas sobre a autodeclaração. A respeito dessa questão de cor ou raça, o IBGE realizou estudos prévios que indicaram que durante a realização do Censo 2010 em terras indígenas, quando a pessoa não se autodeclarasse como indígena, ela deveria responder à pergunta "Você se considera indígena", gerando um grupo de pessoas que não se autodeclararam indígenas, mas se consideraram indígenas dentre a população em TI.

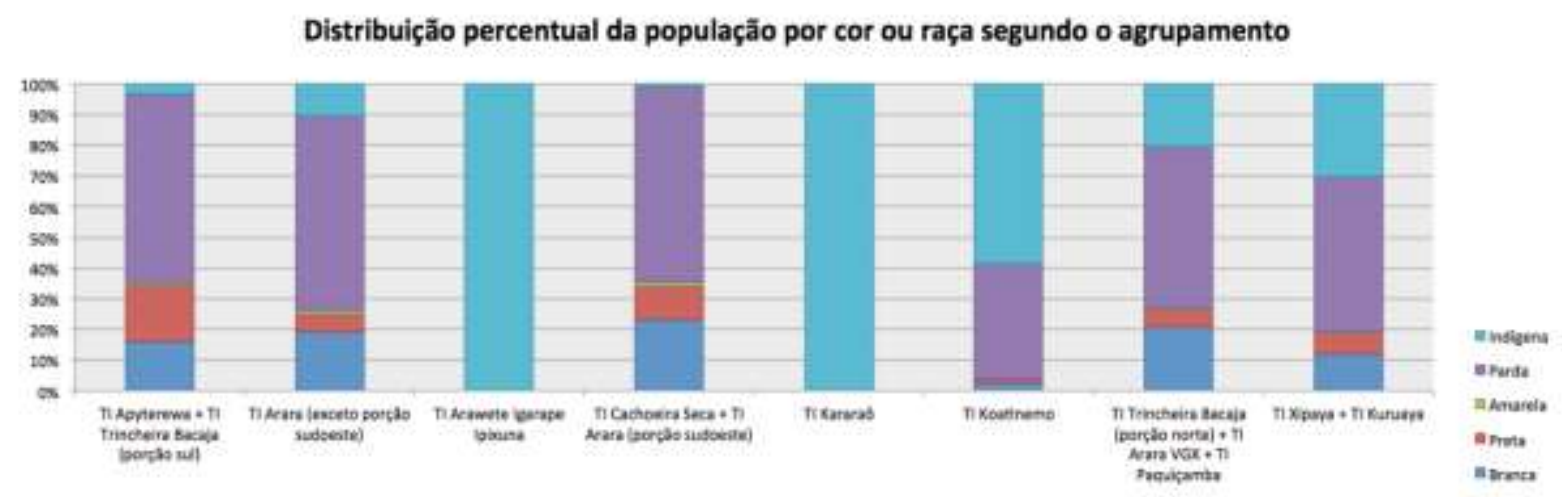

Figura 7 - Distribuição percentual da população por cor ou raça segundo o agrupamento.

A Contagem de 2007 nos fornece informações referentes às variáveis de migração da população (Figura 8). Com isso podemos ver que na "TI Trincheira Bacaja (porção norte) + TI Arara VGX + TI Paquiçamba" $35,10 \%$ da população é considerada migrante, percentual que chega a 0 nas TIs Arawete Igarape Ipixuna, TI Kararaô" e TI Koatinemo". Neste caso é preciso atentar para o volume pequeno de migrantes, pois em algumas áreas o percentual pode parecer elevado enquanto estamos tratando de pequenas populações. Em apenas três áreas com maior percentual de migrantes é que o volume ultrapassa 1000 pessoas, ao passo que nas outras áreas, por exemplo a "TI Arara (exceto porção sudoeste)" os 6,35\% de população migrante correspondem a somente 126 pessoas.

Interessante notar que as três áreas com maior percentual de indígenas em 2010 (TI Arawete Igarape Ipixuna, TI Kararaô e TI Koatinemo) são as três áreas que apresentaram 0\% de população migrante em 2007. Isso pode indicar a hipótese de que a população migrante em Tls é em geral formada por não indígenas. 


\section{Percentual de população migrante em 2007}

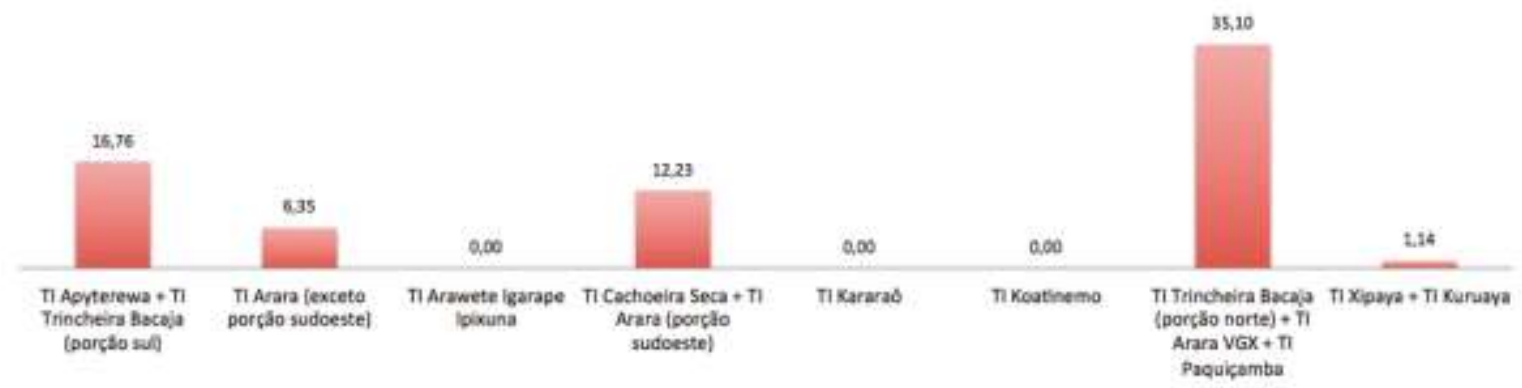

Figura 8 - Percentual de população migrante em 2007 nos agrupamentos de Tls.

A Figura 9 apresenta a distribuição percentual da população migrante segundo a origem. Nos agrupamentos, a origem dos migrantes é predominantemente de outros municípios do Pará, indicando que a região segue uma tendência nacional de grande relevância atualmente que é a circulação interna e de pequenas distâncias da população. Por outro lado, a permanência de uma migração de longa distância pode ser percebida em casos como o da "TI Xipaya + TI Kuruaya" onde, embora com poucos migrantes (são apenas 6 no total, sendo 4 de municípios do Pará e 2 do Paraná) esta distribuição faz com que exista uma grande porcentagem de migrantes da região Sul.

\section{Distribuição percentual da população migrante, segundo a origem}

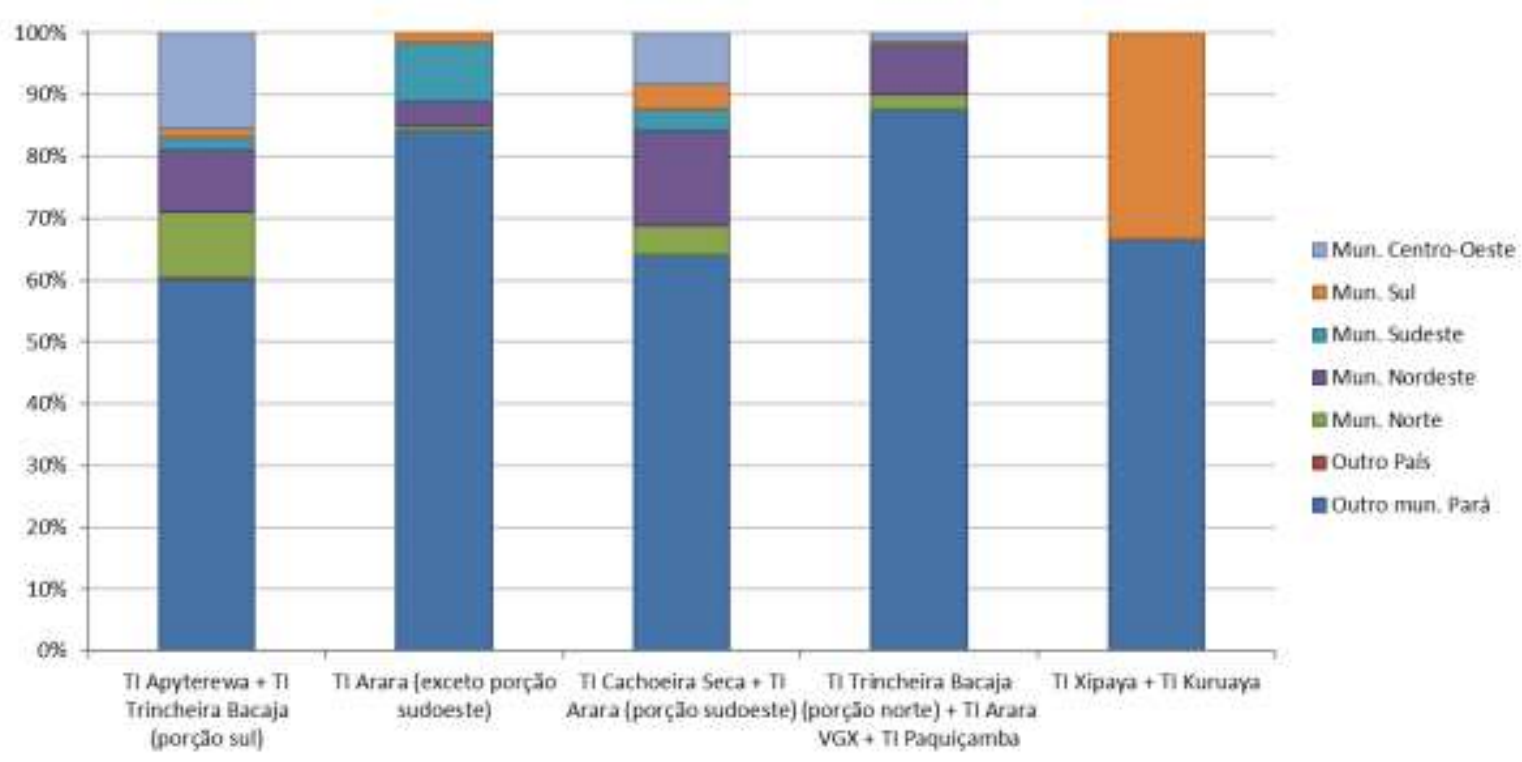

Figura 9 - Distribuição percentual da população migrante em cada agrupamento, segundo a origem. 


\section{Conclusões}

Em síntese, os resultados mostram que a evolução dos indicadores segue algumas tendências verificadas no Brasil como um todo, tal como: envelhecimento da estrutura etária, aumento da renda aliado à redução do analfabetismo, diminuição da razão de sexo e presença de imigrantes de curta distância.

Embora trate-se de setores censitários localizados dentro de Terras Indígenas, mas não exclusivamente dentro, na maior parte das unidades espaciais a população indígena não é predominante, embora em duas delas $100 \%$ da população seja autodeclarada indígena, em grande parte delas há grande percentual de população parda. Os homens predominam em quase todas unidades espaciais, ou seja, RS > 100; trata-se de uma característica geral dos municípios da região, que possuem em média RS $=110$, sendo que nos agrupamentos estudados a RS era 117. Percebe-se uma alteração na estrutura etária, com a diminuição do percentual de crianças e aumento dos idosos e dos adultos. Houve forte diminuição do analfabetismo entre 2000 e 2010, associado ao crescimento da renda em algumas unidades, embora tenha havido diminuição da renda em outras. Com relação aos migrantes, das oito unidades espaciais cinco possuíam imigrantes, sendo que na unidade "TI Trincheira Bacaja (porção norte) + TI Arara VGX + TI Paquiçamba" os imigrantes representavam mais de $1 / 3$ da população. Destaca-se o grande peso dos migrantes de curta distância, provenientes de municípios do próprio estado.

Porém, deve-se ter o cuidado de salientar que se trata de populações que foram agrupadas em unidades espaciais - que foram criadas visando as áreas mínimas comparáveis, condizentes com o objetivo de avaliar os indicadores no tempo - o que pode criar algumas distorções.

\section{Referências}

BIAGIONI, D. Comparação do rendimento - Censos 2000 e 2010. Brasília, 2013.

BRITO, F. Transição demográfica e desigualdades sociais no Brasil. Revista Brasileira de Estudos de População, v. 25, n. 1, p. 5-26, jun. 2008.

CARVALHO, J.; WONG, L. A transição da estrutura etária da população brasileira na primeira metade do século XXI. Cadernos de Saúde Pública, v. 24, p. 597-605, 2008.

CUNHA, T.; CUNHA, J.; JAKOB, A. Dinâmica intraurbana e redes sociais na Baixada Santista. Revista Brasileira de Estudos de População, vol.30, n.1, pp. 07-33, 2013.

DAGNINO, R.; ESTANISLAU, B. Caracterização do Adensamento Populacional nos Municípios da UHE de Belo Monte: Compatibilização de setores, indicadores e projeção. Relatório de Pesquisa. Altamira, Verthic, 2015.

DAGNINO, Ricardo. Dinâmica demográfica e indicadores socioeconômicos em escala intramunicipal na fronteira: municípios de Altamira e São Félix do Xingu, Estado do Pará, entre 2000 e 2010. Tese (Doutorado) em Demografia. Universidade Estadual de Campinas, Campinas, 2014.

FUNAI - Fundação Nacional do Índio. Dados geográficos. Terra Indígena (Regularizada, Homologada, Declarada, Delimitada e Área em Estudo). Arquivo digital em formato SHP, versão atualizada em 7 de maio de 2014. 
GRISOTTI, M. A construção de relações de causalidade em saúde no contexto da Hidrelétrica de Belo Monte. Ambiente \& Sociedade, São Paulo, v. XIX, n. 2, p. 291 310, abr.-jun. 2016.

HERRERA, J.; MOREIRA, R. Resistência e conflitos sociais na Amazônia paraense: a luta contra o empreendimento Hidrelétrico de Belo Monte. Campo - Território: Revista de Geografia Agrária, v. 8, n. 16, p. 130-151, 2013.

IBGE - Instituto Brasileiro de Geografia e Estatística. Documentação do Arquivo: Censo Demográfico 2000 - Agregado por Setores Censitários dos Resultados do Universo ( $2^{\underline{a}}$ edição). Rio de Janeiro, IBGE, 2003a.

IBGE. Dados do universo agregados por setores censitários do Censo 2000 Estado do Pará. Rio de Janeiro, IBGE, 2003b.

IBGE. Dados do universo agregados por setores censitários da Contagem 2007 - Estado do Pará. Rio de Janeiro, IBGE, 2008.

IBGE. Características étnico-raciais da população: Um estudo das categorias de classificação de cor ou raça - 2008. IBGE, Rio de Janeiro, 2011a.

IBGE. Dados do universo agregados por setores censitários do Censo 2010 Estado do Pará. Rio de Janeiro, IBGE, 2011b.

IBGE. Documentação do Arquivo: Base de informações do Censo Demográfico 2010: Resultados do Universo por setor censitário. IBGE, Rio de Janeiro, 2011c.

JANNUZZI, P. Indicadores sociais no Brasil. Campinas, Ed. Alínea, 2001.

LOMBARDI, T.; SIMONI, A.; CRAICE, C. Categorias raça/cor no censo e a constituição de territorialidade. In: GUEDES, G.R.; OJIMA, R. (Org.). Território, Mobilidade Populacional e Ambiente. Governador Valadares: Univale, 2012. (p. 113-132).

LOMBARDI, T.; SIMONI, A.; ESTANISLAU, B.; DAGNINO, R.; ARRUTI, J. Ethnicity and race data collection at some Latin American countries census. In: XXVII IUSSP International Population Conference, Busan, 2013.

MAGALHÃES, S.; MORAL HERNÁNDEZ, F. Relatório do painel de especialistas. Análise crítica do Estudo de Impacto Ambiental do Aproveitamento Hidrelétrico de Belo Monte. Belém, 2009.

MORAL HERNÁNDEZ, F.; MAGALHÃES, S. Ciência, cientistas e democracia desfigurada: o caso Belo Monte. Novos Cadernos NAEA, Belém, v. 14, n. 1, p. 7996, jun. 2011.

REIS, E.; PIMENTEL, M.; ALVARENGA, A. Áreas mínimas comparáveis para os períodos intercensitários de $\mathbf{1 8 7 2}$ a 2000. IPEA, 2007.

REIS, E.; PIMENTEL, M.; ALVARENGA, A.; SANTOS, M. Áreas mínimas comparáveis para os períodos intercensitários de 1872 a 20001. Anais do 1 Simpósio Brasileiro de Cartografia Histórica. Paraty, 2011.

RENNER, C.; PATARRA, N. Migrações. In: SANTOS, J.; LEVY, M.; SZMRECSÁNYI, T. (org.). Dinâmica populacional: teoria, métodos e técnicas de análise. Primeira reimpressão. São Paulo, T.A. Queiroz, 1991. (p. 236-260). 
RIPSA - Rede Interagencial de informações para a saúde. Indicadores básicos para a saúde no Brasil: conceitos e aplicações. $2^{\underline{a}}$ edição. Brasília: Organização PanAmericana da Saúde, 2008.

SEVÁ FILHO, A. O. (Org.) Tenotã Mõ: alertas sobre as conseqüências dos projetos hidrelétricos no rio Xingu. International Rivers Networks, 2005.

UNESCO. Boletín Proyecto Principal de Educación. Boletín n.32, Diciembre, 1993 apud RIPSA - Rede Interagencial de Informação para a Saúde. Indicadores básicos para a saúde no Brasil: conceitos e aplicações. $2^{\mathrm{a}}$ edição. Brasília: Organização PanAmericana da Saúde, 2008. 349 p. Disponível em:<http://goo.gl/UhPYD>. Acesso em 10 de janeiro de 2012.

WONG, L.; CARVALHO, J. O rápido processo de envelhecimento populacional do Brasil: sérios desafios para as políticas públicas. Revista Brasileira de Estudos de População, v. 23, p. 5-26, 2006. 


\section{Apêndice}

Tabelas com os dados processados para construção dos indicadores dos oito agrupamentos espaciais de Terras Indígenas da Região da Usina Hidrelétrica de Belo Monte.

\begin{tabular}{|c|c|c|c|c|c|c|c|c|c|c|c|c|}
\hline Censo & Agrupamentos espaciais & População & Homens & Mulheres & 0-14 anos & 15-59 anos & $60+$ anos & Razão Sexo & Pop. idade conhecida & Renda & Taxa Analfab. & Renda deflacionada \\
\hline \multirow{8}{*}{2000} & TI Apyterewa + TI Trincheira Bacaja (porção sul) & 3052 & 1697 & 1355 & 1291 & 1655 & 101 & 125,24 & 3047 & 260,69 & 30,25 & 407,17 \\
\hline & TI Arara (exceto porção sudoeste) & 2872 & 1589 & 1283 & 1065 & 1665 & 142 & 123,85 & 2872 & 420,91 & 28,54 & 657,41 \\
\hline & TI Arawete Igarape Ipixuna & 378 & 186 & 192 & 188 & 142 & 38 & 96,88 & 368 & 83,22 & 89,70 & 129,98 \\
\hline & TI Cachoeira Seca + TI Arara (porção sudoeste) & 9446 & 5028 & 4418 & 3779 & 5254 & 413 & 113,81 & 9446 & 377,93 & 23,02 & 590,28 \\
\hline & TI Kararaô & 25 & 13 & 12 & & & & 108,33 & & & & \\
\hline & TI Koatinemo & 215 & 123 & 92 & 86 & 118 & 11 & 133,70 & 215 & 287,08 & 60,93 & 448,39 \\
\hline & TI Trincheira Bacaja (porção norte) + TI Arara VGX + TI Paquiçamba & 1548 & 861 & 687 & 679 & 806 & 63 & 125,33 & 1548 & 185,30 & 46,43 & 289,42 \\
\hline & TI Xipaya + TI Kuruaya & 297 & 172 & 125 & 133 & 152 & 12 & 137,60 & 297 & 199,21 & 57,21 & 311,15 \\
\hline \multirow{9}{*}{2007} & Agrupamentos espaciais & População & Homens & Mulheres & $0-14$ anos & $15-59$ anos & $60+$ anos & Razão Sexo & Pop. idade conhecida & Renda & Taxa Analfab. & Renda deflacionada \\
\hline & TI Apyterewa + TI Trincheira Bacana (porção sul) & 8582 & 4803 & 3726 & 2627 & 5527 & 368 & 128,90 & 8522 & - & - & - \\
\hline & TI Arara (exceto porção sudoeste) & 1985 & 1052 & 784 & 646 & 1092 & 97 & 134,18 & 1835 & - & - & - \\
\hline & TI Arawete Igarape Ipixuna & 483 & 243 & 240 & 252 & 185 & 46 & 101,25 & 483 & - & - & - \\
\hline & TI Cachoeira Seca + TI Arara (porção sudoeste) & 10269 & 5504 & 4657 & 3905 & 5710 & 543 & 118,19 & 10158 & - & - & - \\
\hline & TI Kararaô & 342 & 160 & 178 & 107 & 220 & 11 & 89,89 & 338 & - & - & - \\
\hline & TI Koatinemo & 112 & 61 & 47 & 51 & 55 & 2 & 129,79 & 108 & - & - & - \\
\hline & TI Trincheira Bacaja (porção norte) + TI Arara VGX + TI Paquiçamba & 3376 & 1921 & 1408 & 1325 & 1866 & 135 & 136,43 & 3326 & - & - & - \\
\hline & TI Xipaya + TI Kuruaya & 525 & 301 & 224 & 245 & 262 & 18 & 134,38 & 525 & - & - & - \\
\hline \multirow{9}{*}{2010} & Agrupamentos espaciais & População & Homens & Mulheres & 0-14 anos & $15-59$ anos & $60+$ anos & Razão Sexo & Pop. idade conhecida & Renda & Taxa Analfab. & Renda deflacionada \\
\hline & TI Apyterewa + TI Trincheira Bacaja (porção sul) & 12673 & 6744 & 5929 & 4139 & 8090 & 444 & 113,75 & 12673 & 673,54 & 16,62 & - \\
\hline & TI Arara (exceto porç̧̃o sudoeste) & 2486 & 1379 & 1107 & 889 & 1459 & 138 & 124,57 & 2486 & 618,34 & 25,22 & - \\
\hline & TI Arawete Igarape Ipixuna & 393 & 202 & 191 & 194 & 170 & 29 & 105,76 & 393 & 120,17 & 95,58 & - \\
\hline & TI Cachoeira Seca + TI Arara (porção sudoeste) & 11933 & 6360 & 5573 & 4153 & 6917 & 719 & 114,12 & 11789 & 445,69 & 17,08 & - \\
\hline & TI Kararaô & 59 & 24 & 35 & 21 & 21 & 5 & 68,57 & 47 & 286,88 & 50,00 & - \\
\hline & TI Koatinemo & 237 & 134 & 103 & 111 & 106 & 20 & 130,10 & 237 & 249,52 & 37,27 & - \\
\hline & TI Trincheira Bacaja (porção norte) + TI Arara VGX + TI Paquiçamba & 4251 & 2430 & 1821 & 1552 & 2441 & 198 & 133,44 & 4191 & 315,51 & 24,73 & - \\
\hline & TI Xipaya + TI Kuruaya & 669 & 387 & 282 & 266 & 384 & 16 & 137,23 & 666 & 521,90 & 27,66 & - \\
\hline
\end{tabular}




\begin{tabular}{|c|c|c|c|c|c|c|c|c|c|}
\hline \multirow{9}{*}{$\begin{array}{c}200 \\
7\end{array}$} & Agrupamentos espaciais & $\begin{array}{l}\text { Migrantes de outros municípios do } \\
\text { Pará PA }\end{array}$ & $\begin{array}{l}\text { Mig. } \\
\text { Internacionais }\end{array}$ & $\begin{array}{l}\text { Mig. } \\
\text { Norte }\end{array}$ & $\begin{array}{l}\text { Mig. } \\
\text { Nordeste }\end{array}$ & $\begin{array}{l}\text { Mig. } \\
\text { Sudeste }\end{array}$ & $\begin{array}{l}\text { Mig. } \\
\text { Sul }\end{array}$ & $\begin{array}{l}\text { Mig. Centro- } \\
\text { Oeste }\end{array}$ & $\begin{array}{l}\text { Migrante } \\
\mathrm{s}\end{array}$ \\
\hline & TI Apyterewa + TI Trincheira Bacaja (porção sul) & 868 & 1 & 154 & 142 & 30 & 21 & 222 & 1438 \\
\hline & TI Arara (exceto porção sudoeste) & 106 & 0 & 1 & 5 & 12 & 2 & 0 & 126 \\
\hline & TI Arawete Igarape Ipixuna & 0 & 0 & 0 & 0 & 0 & 0 & 0 & 0 \\
\hline & TI Cachoeira Seca + TI Arara (porção sudoeste) & 803 & 0 & 59 & 194 & 42 & 50 & 105 & 1256 \\
\hline & TI Kararaô & 0 & 0 & 0 & 0 & 0 & 0 & 0 & 0 \\
\hline & $\begin{array}{l}\text { TI Koatinemo } \\
\text { TI Trincheira Bacaja (porção norte) + TI Arara VGX + TI }\end{array}$ & 0 & 0 & 0 & 0 & 0 & 0 & 0 & 0 \\
\hline & Paquiçamba & 1038 & 0 & 28 & 95 & 4 & 3 & 17 & 1185 \\
\hline & TI Xipaya + TI Kuruaya & 4 & 0 & 0 & 0 & 0 & 2 & 0 & 6 \\
\hline
\end{tabular}

\begin{tabular}{|c|c|c|c|c|c|c|}
\hline \multirow{9}{*}{2010} & Agrupamentos espaciais & Brancos & Pretos & Amarelos & Pardos & Indígenas \\
\hline & TI Apyterewa + TI Trincheira Bacaja (porção sul) & 2015 & 2309 & 130 & 7826 & 393 \\
\hline & TI Arara (exceto porção sudoeste) & 480 & 147 & 32 & 1564 & 263 \\
\hline & TI Arawete Igarape Ipixuna & 0 & 0 & 0 & 0 & 393 \\
\hline & TI Cachoeira Seca + TI Arara (porção sudoeste) & 2726 & 1306 & 145 & 7503 & 109 \\
\hline & TI Kararaô & 0 & 0 & 0 & 0 & 47 \\
\hline & TI Koatinemo & 6 & 3 & 0 & 89 & 139 \\
\hline & TI Trincheira Bacaja (porção norte) + TI Arara VGX + TI Paquiçamba & 865 & 232 & 25 & 2221 & 848 \\
\hline & TI Xipaya + TI Kuruaya & 80 & 46 & 1 & 338 & 201 \\
\hline
\end{tabular}

